\title{
LA COMUNICACIÓN CON IDENTIDAD. REGULACIONES Y UN ESTUDIO DE CASO
}

\section{Communication with Identity. Regulations and a Case Study}

\section{A comunicação com identidade. Regulações e um estudo de caso}

Norma Liliana Lizondo, Sede Regional Tartagal, Universidad Nacional de Salta, Argentina kopan63@gmail.com

\section{RESUMEN}

El siguiente artículo analiza los alcances de la comunicación con identidad en el marco de la aprobación de la Ley de Servicios de Comunicación Audiovisual en Argentina. Los pueblos originarios hicieron llegar a los foros de consulta, previos a la aprobación de la ley, sus voces con la demanda del derecho a la comunicación y con una categoría que emergió en el campo de las ciencias sociales: comunicación con identidad. El artículo también revisa esa categoría en el contexto de una experiencia desarrollada en el norte de Argentina desde el año 2001; la zona en la que emite la radio es rica en diversidad, ya que habitan siete pueblos originarios, criollos e inmigrantes europeos y árabes.

Palabras clave: comunicación con identidad, marcos regulatorios, radios indígenas.

\section{ABSTRACT}

The following article analyzes the scope of communication with identity within the framework of the approval of the Audiovisual Communication Services Act in Argentina. The indigenous peoples sent to the consultation forums, prior to the approval of the law, their voices with the demand for the right to communication and with a category that 
emerged in the field of social sciences: communication with identity. This article also reviews this category in the context of an experience developed in northern Argentina since 2001, the area in which the radio broadcasts is rich in diversity as it inhabits seven native peoples, Creoles and immigrants from Europe and Syria.

Keywords: Communication with identity, regulatory frameworks, indigenous radios.

\begin{abstract}
RESUMO
O seguinte artigo analisa os alcances da comunicação om identidade no marco da aprovação da Lei de Serviços de Comunicação Audiovisual na Argentina. Os povos originários fizeram chegar aos foros de consulta, prévios à aprovação da lei, suas vozes com a demanda do direito à comunicação e com uma categoria que emergiu no campo das ciências sociais: comunicação com identidade. 0 artigo também revisa essa categoria no contexto de uma experiência desenvolvida no norte da Argentina desde o ano 2001, a zona na que emite a rádio é rica em diversidade já que habitam 7 povos originários, crioulos e imigrantes europeus e árabes.
\end{abstract}

Palavras-chave: comunicação com identidade, marcos regulatórios, rádios indígenas.

La investigación en comunicación en América Latina produjo un conocimiento capaz de incidir en la conformación del campo disciplinar propio, sin embargo, fue dejando de lado temas nodales. Son esos temas los que aparecen hoy en las agendas de la academia, casi como repitiendo la historia de la comunicación comunitaria, alternativa o popular; se indaga sobre ellos cuando ya son realidades consolidadas en el espectro radioeléctrico. Este es el contexto en el que la comunicación gestionada por pueblos originarios se incluye en el campo de estudio de las ciencias sociales.

Coincidiendo con la afirmación de Marques de Melo (1998), se comparte la certeza de la conformación de lo que el autor brasilero denomina "escuela latinoamericana de la comunicación". Esta puso en debate la concepción de la comunicación como información para hacer emerger temas como la comunicación para el desarrollo -cuestionada unos años más tarde- o la necesidad de un orden más equilibrado en la circulación de la información. Si bien las indagaciones en torno a una versión menos instrumental de la comunicación se genera desde un sesgo latinoamericano, esto no llevó a incluir entre las particularidades de la región a los pueblos originarios.

La mencionada carencia se agudiza aún más cuando se pone el foco en la comunicación desarrollada previa a la Conquista. El tema fue explicitado por Luis Ramiro Beltrán y otros investigadores bolivianos en un texto de 2008 que analiza las formas de comunicación antes de la llegada de Colón al continente. El mismo artículo da continuidad a la línea de pensamiento latinoamericano que centra la crítica en una concepción de la comunicación como instrumento o del modo difusionista. Con ello, los autores insistieron como propio el carácter constitutivo de la comunicación en la sociedad. 


\section{DISERTACIONES}

ESTUDIOS

Comunicación indigena en América Latina

ISSN: 1856-9536

Doi: http://dx.doi.org/10.12804/revistas.urosario.edu.co/disertaciones/a.5745

Volumen 11, Número 2 / Julio-diciembre 2018

Versión PDF para imprimir desde

http://revistas.urosario.edu.co/index.php/disertaciones

Otro de los aspectos que se hace necesario señalar al momento de indagar sobre la comunicación indígena es la función que cumplen los marcos regulatorios para los servicios audiovisuales. Las posiciones respecto al rol del Estado como garante del derecho a la comunicación para los indígenas varían en los países de este continente, aunque efectivamente han marcado fuertemente la existencia o no de medios de gestión indígena.

Los medios comunitarios, alternativos o populares, y los medios de gestión indígena no fueron considerados en Argentina como posibles prestadores de servicios audiovisuales hasta la aprobación de la Ley 26522. ${ }^{1}$ En realidad, lo que viene a hacer la ley es legitimar la existencia de los medios sin fines de lucro que, en Argentina, se desarrollaron con más lentitud que en el resto del continente. Esta inclusión, sin embargo, no se realizó bajo las condiciones que establecía el proyecto original de la ley, sino que tuvo modificaciones derivadas de los reclamos de los comunicadores indígenas, quienes demandaron no ser considerados como medios comunitarios. Aquí es cuando la comunicación con identidad se presenta como categoría en el marco de los medios contrahegemónicos.

Por último, este artículo se detiene en una experiencia pionera en el norte de Argentina. Se trata de un medio con características particulares por el modo en que se fue convirtiendo de un proyecto surgido en la universidad a un proyecto político comunicacional con verdadera incidencia en la comunidad y con un rol articulador de reclamos sobre la propiedad de la tierra.

Otra inquietud que sedimenta la producción de este texto es la preocupación por generar conocimiento sobre comunicación indígena y, específicamente, la comunicación en FM Comunitaria La Voz Indígena. ${ }^{2}$ Este interés hace necesario consolidar otras problemáticas, como la falta de bibliografía que dé cuenta de los modos de comunicación de los pueblos originarios; las similitudes que tienen los actores sociales de la comunicación indígena con los sujetos de la comunicación popular, alternativa o comunitaria; las implicancias políticas del concepto comunicación con identidad ${ }^{3}$ generado por los comunicadores indígenas durante el proceso de aprobación de la Ley de Servicios de Comunicación Audiovisual; las consecuencias de una política pública que tiene como objetivo uno de los sectores más marginales de la sociedad.

Esas preocupaciones se reflejan en las siguientes interrogaciones:

- ¿La fm Comunitaria La Voz Indígena se inscribe en las características que asume la comunicación con identidad?

- ¿La comunicación con identidad tiene características que la diferencian de la comunicación alternativa?

- ¿La teoría existente sobre medios contrahegemónicos es aplicable a la comunicación indígena?

1 La Ley 26522 de Servicios de Comunicación Audiovisual aprobada en Argentina en el año 2009 está sufriendo modificaciones a partir del advenimiento del gobierno encabezado por Mauricio Macri. Si bien los artículos referidos a los pueblos indígenas aún no se modificaron, el giro que va tomando es desalentador.

2 Primera radio de gestión indígena en Tartagal, Salta, norte de Argentina.

3 Comunicación con identidad es la denominación que los pueblos originarios de Argentina decidieron para ser nombrados por el Estado al momento de los debates previos a la aprobación de la Ley de Servicios de Comunicación Audiovisual. La insistencia en no ser considerados como medios comunitarios, alternativos o populares se mantuvo durante todo el proceso y, a pesar de no estar reconocida la comunicación con identidad en la ley ni en su reglamentación, las políticas de comunicación que se generaron de modo posterior se refirieron a la comunicación con identidad como la actividad ejercida por los pueblos originarios. 


\section{DISERTACIONES}

ESTUDIOS

Comunicación indigena en América Latina

ISSN: 1856-9536

Doi: http://dx.doi.org/10.12804/revistas.urosario.edu.co/disertaciones/a.5745

Volumen 11, Número 2 / Julio-diciembre 2018

Versión PDF para imprimir desde

http://revistas.urosario.edu.co/index.php/disertaciones

- ¿La comunicación, en casos de multiculturalidad, es la misma para las comunidades donde se habla el español y otra lengua que para las comunidades donde coexisten ocho lenguas?

El enfoque metodológico de la pesquisa es de corte cualitativo, asentado en la investigación documental de tipo interpretativo en temas como la evolución del derecho a la comunicación indígena, en el análisis de distintas teorías sobre comunicación popular e indígena y, finalmente, sobre la categoría identidad, vinculada con la cultura. La escucha de las emisiones de la FM Comunitaria La Voz Indígena forma parte también del corpus del texto. En tal sentido se realizaron:

- Análisis de la programación de la radio.

- Entrevistas a comunicadores indígenas.

- Observación participante en la gestión de la Radio Comunitaria La Voz Indígena.

- Sistematización de la información relevada para la construcción de rasgos que definan o diferencien ambos tipos de comunicación.

- Análisis de los modos de vinculación de la radio La Voz Indígena con la comunidad indígena.

\section{Los pueblos indígenas y la relación con el Estado}

El violento proceso de colonización en América no culminó cuando se conformaron los Estados nacionales, por el contrario, continuó con la República, desde donde se generaron instrumentos legales para el despojo de sus tierras, de su cultura y de su palabra. La independencia de la corona española podría haber supuesto el surgimiento de una república indígena; esta posibilidad no logró el consenso necesario y se conformó el Estado bajo el modelo europeo, lo que implicó dejar de lado cualquier tipo de derecho para los pueblos que ya habitaban el continente.

Los procesos de conformación de las repúblicas fueron similares a las posiciones de ultramar y se generaban de dos formas: se legitimaba el exterminio - caso de Argentina - o se desconocía la existencia de diversidad cultural, conformando repúblicas homogéneas. A través de este proceso se les vedó, entre otros derechos, de la participación política y de la posibilidad de ejercer la ciudadanía.

El derecho a la comunicación integra el repertorio de los derechos negados junto a una larga lista de exclusiones que deslegitimaron su existencia y garantizaron el proceso de saqueo de la tierra. La aclaración resulta necesaria porque para el mundo indígena la tierra es un elemento vertebrador de la cultura, ya que nuclea la vida a su alrededor, distanciándose de la mirada occidental, que la considera desde una perspectiva extractivista. La tierra es el espacio donde se despliega la comunicación que no está mediada por la tecnología, es el lugar de diálogo con la naturaleza.

Los años que siguieron a la conformación del Estado-nación agudizaron el despojo, además de la progresiva pérdida de la tierra, lo que también implicó la consideración del trabajo de manos indígenas como esclavo. El largo proceso de militancia por esos derechos fue lo que llevó a la Organización de las Naciones Unidas a revisar la situación de los pueblos originarios como sujetos de derecho.

Hacia fines del siglo xx, los derechos indígenas comenzaron a ser reconocidos por los Estados a nivel mundial, esto gracias al trabajo de organizaciones indígenas de todo el mundo que advertían en la Declaración de los Derechos Humanos la ausencia de apartados referidos específicamente a los grupos aborígenes. En este sentido, la 


\section{DISERTACIONES}

ESTUDIOS

Comunicación indigena en América Latina

ISSN: 1856-9536

Doi: http://dx.doi.org/10.12804/revistas.urosario.edu.co/disertaciones/a.5745

Volumen 11, Número 2 / Julio-diciembre 2018

Versión PDF para imprimir desde

http://revistas.urosario.edu.co/index.php/disertaciones

Declaración de las Naciones Unidas por los derechos indígenas marca un nuevo paradigma en materia de derecho, porque en su texto explicita la existencia de los pueblos originarios.

En relación con este tema se puede coincidir con Lizondo y Ortega (2013, p. 5) cuando aseguran que "la garantía del derecho a la comunicación para los pueblos aborígenes forma parte de una serie de reivindicaciones que se generan desde la recuperación de la democracia en Argentina. De esta suerte, el Estado nacional es un actor relevante para garantizar los derechos y las demandas necesarias debido al despojo que sufrieron durante cientos de años y que los expuso y expone a situaciones de extrema vulnerabilidad". En la actualidad, en América Latina, existen políticas destinadas a garantizar el derecho a la comunicación indígena. Del mismo modo, existen movimientos, foros, congresos o encuentros que reclaman ese derecho y su efectivo ejercicio.

Los pueblos indígenas gestionaron sus voces en todo el continente mucho antes de que la legislación garantizara esa posibilidad. Ocurrió en Argentina antes de la Ley 26522, ya que los medios existían pero eran ilegales y corrían la misma suerte que los medios comunitarios. Es necesario destacar que el proceso que condujo a la aprobación de la Ley de Servicios de Comunicación Audiovisual tuvo como motor principal a la Coalición por una Radiodifusión Democrática, ${ }^{4}$ espacio en el que militaron sectores gremiales, universitarios y organizaciones de base; los pueblos originarios se integran a la Coalición ante la inminencia de la aprobación de la ley, es decir, mucho tiempo después de las otras organizaciones. En este proceso fue el Foro Argentino de Radios Comunitarias (Farco) el que habilitó las voces indígenas en la Coalición hasta que se produjo la incorporación al organismo multisectorial.

La radio que analizamos en el presente artículo inició los trámites a través de la Resolución 753 del Comfer, ${ }^{5}$ lo que impide aún hoy el otorgamiento de la licencia, pues la Ley 26522 considera a una comunidad de pueblos originarios y el medio de Tartagal nuclea a siete pueblos en el mismo dial.

\section{La ausencia de la comunicación indígena en la academia}

Las prácticas de comunicación alternativa fueron realidades concretas desde 1947, con actores sociales involucrados y con proyectos políticos de liberación en marcha. Mucho tiempo después, la investigación latinoamericana se detuvo a pensar en ellas como hecho teórico.

A pesar de los debates generados en la academia latinoamericana, aún no se pueden establecer categorías en las que podamos ubicar la comunicación comunitaria, alternativa o popular. Tampoco es un debate que, a nuestro criterio, resignifique el norte que sí hay en común entre este tipo de medios: la emancipación política es la matriz que los atraviesa.

En un trabajo de recuperación sobre las luchas de los pueblos indígenas y el modo en que aparecen en la producción de medios masivos, Doyle (2012, p. 1) afirma que para analizar la apropiación que hacen las comunidades

4 Se autodefine como organización de organizaciones y desde la aprobación de la Ley de Servicios de Comunicación Audiovisual se llama Coalición por una Comunicación Democrática.

5 Comité Federal de Radiodifusión, fue el organismo creado por la Ley 22283 encargado de la regulación, control y fiscalización de los servicios audiovisuales. Estaba integrado por un representante del Ejército, uno de la Armada y uno de la Fuerza Aérea. La ley de la dictadura se fue modificando en los gobiernos democráticos hasta la aprobación de la Ley 26522.

$$
54
$$




\section{DISERTACIONES}

ESTUDIOS

Comunicación indigena en América Latina

ISSN: 1856-9536

Doi: http://dx.doi.org/10.12804/revistas.urosario.edu.co/disertaciones/a.5745

Volumen 11, Número 2 / Julio-diciembre 2018

Versión PDF para imprimir desde

http://revistas.urosario.edu.co/index.php/disertaciones

indígenas de los medios masivos se debe volver a mirar la década de los cincuenta, momento de fuerte actividad en los medios alternativos, muchos de ellos vinculados con la Iglesia católica.

Esas experiencias, dice Doyle, se situaban en espacios en los que solo se hablaban los idiomas nativos, por lo que los religiosos o los educadores debían aprender a hablar estas lenguas. En relación con la autodenominación de los comunicadores, asevera que no eran nombrados como pueblos originarios, sino como campesinos o mineros, es decir, como integrantes de los sectores populares. ${ }^{6}$

En lo temporal, se puede referir la emergencia de los medios indígenas al mismo tiempo que los de la comunicación comunitaria, alternativa o popular en Latinoamérica. Ambos nacen con el advenimiento de la democracia en la región, desde aquella época son muchas las organizaciones indígenas que generaron estrategias mediáticas para hacer pública la demanda de derechos y para poner en cuestión a una Argentina, supuestamente, 'bajada de los barcos'.

La estrategia, en muchos casos, tuvo la particularidad de no ser una realidad mediada por la mirada blanca, sino por una voz propia, descolonizadora y, como tal, con una dimensión pública de la comunicación indígena, mediada a través de la tecnología. Esta emergencia de temáticas indígenas con voz propia en los medios se carga de un valor político similar al de los medios contrahegemónicos.

Desde una perspectiva política es destacable lo que significa para el espacio público poder escuchar radios que se expresen en varios idiomas que hasta hace poco no eran reconocidos. Tampoco se pueden dejar de considerar los contenidos a los que refieren esos mensajes: la recurrencia al reclamo por la tierra, el cuidado del medio ambiente, la educación intercultural bilingüe o la descolonización de la enseñanza de la historia. Temáticas como el acceso a la tierra, el cuidado del medio ambiente, el reclamo por una educación bilingüe e intercultural, la resistencia indígena a la colonización expresadas desde las propias lenguas generan efectos de sentidos.

En el análisis de una experiencia de la Facultad de Periodismo y Comunicación Social de la Universidad Nacional de La Plata realizada en la provincia de Formosa, ${ }^{7}$ Huergo, Morawicki y Ferreyra (2006) advierten sobre los riesgos de asumir la voz propia, porque hay que poner en común las particularidades o gustos que pueden no ser puros. Aseguran que de los pueblos originarios se espera que la palabra propia tenga vinculación con lo ancestral o con lo exótico, es decir que esté en sintonía con las representaciones que existen en el imaginario social sobre el mundo indígena, y alentar las producciones que no están relacionadas con esa perspectiva podría ayudar a desnaturalizar esas imágenes. Con relación a los espacios interculturales afirman:

Por lo demás, el diálogo intercultural puede comprenderse de dos maneras. Una, como el espacio comunicacional en que la comunidad habla y a la vez es hablada (Bajtín, 1981), y que es en esas formas de hablar donde carga esas características configuradoras de lo global/local. La otra, como proyecto político que hace posible la comprensión y la transformación de un mundo común -en el sentido del diálogo freireano (Freire, 1973)-,

6 En Argentina se abrió un debate sobre los modos de denominación de la comunicación con identidad, diferenciándola de la comunicación campesina. Parte del problema de este debate es cómo denominar a los indígenas que son campesinos. Estos debates, a partir del gobierno del presidente Macri, fueron dando lugar más a las condiciones materiales para la existencia. Es decir, se retrocede en un debate que podría haber enriquecido el campo para volver a la sustentabilidad económica de estos medios.

7 Formosa es una provincia del norte de Argentina con alta concentración de pueblos indígenas. 


\section{DISERTACIONES}

ESTUDIOS

Comunicación indigena en América Latina

ISSN: 1856-9536

Doi: http://dx.doi.org/10.12804/revistas.urosario.edu.co/disertaciones/a.5745

Volumen 11, Número 2 / Julio-diciembre 2018

Versión PDF para imprimir desde

http://revistas.urosario.edu.co/index.php/disertaciones

o la lectura/escritura del mundo, pero no ya separando a las instituciones políticas formales (como los partidos políticos) de las prácticas políticas culturales particulares (como las formas de organización, circulación y distribución del poder en la cultura aborigen, por ejemplo), sino comprendiéndolas como articuladas. Es decir, el diálogo intercultural es con unos sujetos que no son simplemente 'exóticos' por ser aborígenes, sino que pertenecen a un ambiente cultural y político complejo (Huergo, Morawicki y Ferreyra, 2006, p. 108).

\section{La comunicación con identidad}

La problemática de la identidad responde a múltiples enfoques desde las ciencias sociales, en el caso específico de este artículo interesa la dimensión que adquiere el concepto en el marco de la emergencia de los pueblos originarios como productores audiovisuales a partir de la legitimidad otorgada por la Ley 26522.

En el camino que entrecruza la comunicación y la identidad, encontramos otra perspectiva que las vincula: la política. Ella establece relaciones desde el Estado, la nación y las diversidades incluidas en ellas que pugnan por escapar de las tipificaciones unificadoras. Esta forma de abordaje se desarrolla en el texto de Alejandro Grimson (2001) Interculturalidad y comunicación, donde señala que los estudios producidos sobre la nación generan la tensión lógica entre heterogeneidades y homogeneidades. Para superar la dicotomía, cita a Rita Segato, quien propone volver a pensar las relaciones entre cultura, nación y Estado. El texto tiene un gran valor porque analiza las tensiones que se generan entre el Estado y la nación en la configuración de identidades. Por un lado, se encuentra el interés del Estado en unificar las diversidades y, por el otro, las estrategias que ponen en juego los distintos sectores sociales para diferenciarse. Es en ese espacio donde se generan políticas específicas de diferenciación, como puede ser la comunicación con identidad.

El concepto de nación en un contexto como el de este texto - nación argentina, nación wichí, nación guaranípuede dar lugar a una teorización que nos aleje de la búsqueda inicial. Es así que hay que realizar un recorte que proteja de esos posibles desvíos. En Interculturalidad y comunicación, al analizar el tema el autor concluye que "la nacionalidad, por una parte, se refiere al acceso de los derechos y ciudadanía y, por otra, es la vivencia subjetiva de la nación como parámetro de relación e interacción entre personas y grupos sociales" (Grimson, 2001, p. 39). Continúa con la caracterización de tres aspectos que brindan pautas pasibles de ser aplicadas en la comunicación con identidad, ellas son: campo de interlocución, caja de herramientas identitarias y sentido de las categorías. Para referir al campo de interlocución, afirma que el contexto temporoespacial es el marco necesario para las interlocuciones, definiéndolo así:

Un campo de interlocución es un marco dentro del cual ciertos modos de identificación son posibles mientras otros quedan excluidos. Entre los modos posibles de identificación, existe una distribución desigual del poder. Cada Estado nacional constituye un campo de interlocución en el cual actores y grupos se posicionan como parte del diálogo y el conflicto con otros actores y grupos. El Estado-nación es uno de los muchos campos de interlocución, pero aquí nos interesa particularmente por la relevancia política, cultural, cognitiva y afectiva que ha tenido en los últimos siglos (Grimson, 2001, p. 41).

En relación con las otras dos nociones, caja de herramientas identitarias y sentido de las categorías, el investigador argentino destaca la creación de categorías que pueden ser definidas como "caja de herramientas identitarias"; los actores no deben tomar todas de una vez, sino que se puede ir alternando al momento de convertirse en interlo- 


\section{DISERTACIONES}

ESTUDIOS

Comunicación indigena en América Latina

ISSN: 1856-9536

Doi: http://dx.doi.org/10.12804/revistas.urosario.edu.co/disertaciones/a.5745

Volumen 11, Número 2 / Julio-diciembre 2018

Versión PDF para imprimir desde

http://revistas.urosario.edu.co/index.php/disertaciones

cutor, con ello los modos de inclusión en diferentes contextos cobran fuerza en algunos momentos y en otros la pierden. El antropólogo asegura que "las sociedades comparten esa caja de herramientas y comparten los criterios de interlocución. Sin embargo, los sentidos de cada una de las categorías son uno de los principales objetos de disputa en la lucha social" (Grimson, 2001, p. 45).

Los comunicadores indígenas que optaron por la comunicación con identidad como forma de denominación para los servicios audiovisuales de los que pueden ser prestatarios legitimaron un modo de presentarse ante el Estado. Una de las razones que explican esta decisión la podemos encontrar también en Grimson (2001, p. 42), quien entiende que los movimientos sociales recurren a la legitimación de sus espacios para presentarse como un interlocutor ante el Estado. Quizá sea el momento de ampliar esa interacción abrevando de la "etnopolítica".

La Ley 26522 refiere específicamente a los medios audiovisuales de gestión indígena. Sin embargo, los comunicadores no se conformaron con la autorización directa, sino que insistieron en una forma de comunicación que pueda diferenciarlos de medios con similares características. En esta pugna, se evidencia que una minoría que lucha por el reconocimiento se apropia de una categoría como herramienta política para resignificar su sentido. Resuena en ello la afirmación foucaultiana de que la teoría debe funcionar como una caja de herramientas puesta al servicio de las luchas del presente. En palabras del pensador francés:

Entender la teoría como una caja de herramientas quiere decir: que no se trata de construir un sistema sino un instrumento, una lógica propia a las relaciones de poder y a las luchas que se comprometen alrededor de ellas; que esta búsqueda no puede hacerse más que poco a poco, a partir de una reflexión (necesariamente histórica en algunas de sus dimensiones) sobre situaciones dadas. A ello puede sumarse que toda herramienta puede ser un arma, según cómo se utilice (Foucault, 1985, p. 85).

De esta manera, a partir de los aportes de la antropología sobre la cuestión de la identidad étnica y la compleja forma de su existencia, es posible operar con nuevos elementos en un campo de mucha relevancia para la historia de la comunicación comunitaria: la dimensión político-cultural de los medios comunitarios.

Es esta dimensión la que ha servido para distinguir a un medio de comunicación comunitaria de los medios públicos y comerciales. En una historia de más de medio siglo de este tipo de comunicación, la identidad de sus medios osciló entre el propósito de la salvación religiosa, la alfabetización y la emancipación política revolucionaria de corte marxista. Siguiendo a Deleuze (1996), consideramos de gran relevancia que la comunicación con identidad se instale con insistencia en el seno de los actuales procesos de redefinición del componente emancipatorio de la comunicación social en general y de la comunicación comunitaria en particular. Que las minorías étnicas de Argentina luchen por convertirse en mayoría, a partir del reconocimiento de sus derechos bajo la forma de la identidad,

8 El término resulta útil para referir a las políticas públicas que den cuenta de la diversidad cultural; Zambrano (2006, p. 230) en un texto que analiza la relación de la política y la diversidad expresa que "son las ideologías de cohesión, culturalmente determinadas, que se presentan como respuesta a los desafíos que imponen la diversidad étnica y cultural - a sí mismas, a las sociedades, a las etnias, a las naciones y a los Estados- para alcanzar los derechos históricos que reclaman, construir libertades culturales, conseguir los niveles de inclusión indispensables para su participación política y desplegar el reconocimiento de la legitimidad de sus contribuciones en la delineación de los trazos de la convivencia multicultural y/o el Estado multicultural o Estado pluralista social del derecho". 


\section{DISERTACIONES}

ESTUDIOS

Comunicación indigena en América Latina

ISSN: 1856-9536

Doi: http://dx.doi.org/10.12804/revistas.urosario.edu.co/disertaciones/a.5745

Volumen 11, Número 2 / Julio-diciembre 2018

Versión PDF para imprimir desde

http://revistas.urosario.edu.co/index.php/disertaciones

nos incita a ver cuánto del devenir minoritario que anima a ese proyecto puede impulsar las búsquedas de transformación emancipadora de nuestros propios procesos, expresados en la comunicación comunitaria.

\section{Las radios indígenas del norte de Argentina, el caso de la fm Comunitaria La Voz Indígena}

Los procesos de reivindicaciones que se generan desde los diferentes espacios sociales deben ser interpretados desde el contexto en que emergen. En este sentido, se sitúa el nacimiento de la fm Comunitaria La Voz Indígena en el marco de los movimientos indigenistas del continente que, desde principios de los ochenta, reclamaron el derecho a la comunicación y se fueron apropiando de las tecnologías existentes para su ejercicio. Ese momento marcó también un aumento en las demandas de visibilidad de las comunidades indígenas, ya que no solo se reclamaba la tenencia de tierras, la educación intercultural, el respeto a las creencias, sino también una legislación en la que los medios indígenas estén incluidos.

Se puede citar, a modo de ejemplo, la reforma constitucional de Colombia que en 1991 cede la administración de los temas específicos a las autoridades indígenas. Con relación al espectro radioeléctrico, garantiza el acceso de las comunidades. Como señalan Rodríguez y El'Gazi (2007, p. 239): "En Colombia las emisoras indígenas de radio obtuvieron sus licencias como 'radios de interés público', una categoría legal reservada hasta entonces para aquellas licencias de radio asignadas a entidades públicas como gobiernos municipales o universidades públicas".

Experimentada como una conquista etnopolítica, la aprobación de la Ley de Servicios de Comunicación Audiovisual estimuló la continuidad del debate sobre el sentido que la comunicación indígena adquiría en el marco de las transformaciones que se estaban produciendo.

Esta conquista también se materializó en una intensa demanda de autorizaciones directas para medios indígenas a lo que hasta diciembre de 2015 fue la Autoridad Federal de Comunicación Audiovisual, ${ }^{9}$ muchos de los que aún hoy se encuentran al aire. A partir de 2009, los comunicadores con formación en medios recorrieron la Argentina con talleres de capacitación fomentando el establecimiento de medios indígenas. En Salta y Jujuy se encendieron radios que aún siguen funcionando, entre ellas: ғM Ocan en Nazareno, fm Ambrosio en Cachi, fm Libertad en Molinos o fm Pachakuti en Abra Pampa.

La lista de las radios referencia el valor que les dan los pueblos originarios a la comunicación mediada por la tecnología. Ven en ella el modo de hacer pública la demanda por la tierra, pero también un instrumento para la conservación de la cultura. Estos detalles se visibilizarán en el análisis de la FM Comunitaria La Voz Indígena, que se considera como experiencia pionera en radio indígena porque preexistió a la ley.

\section{La Voz Indígena}

El colectivo de comunicación que hoy lleva adelante la fM Comunitaria La Voz Indígena inició sus actividades en 1998 integrado por comunidades aborígenes de todo el departamento General San Martín de la provincia de

9 A partir de la presidencia de Macri y del Decreto de Necesidad y Urgencia 267/15, se convirtió en Ente Nacional de Comunicación. 


\section{DISERTACIONES}

ESTUDIOS

Comunicación indigena en América Latina

ISSN: 1856-9536

Doi: http://dx.doi.org/10.12804/revistas.urosario.edu.co/disertaciones/a.5745

Volumen 11, Número 2 / Julio-diciembre 2018

Versión PDF para imprimir desde

http://revistas.urosario.edu.co/index.php/disertaciones

Salta ${ }^{10}$ y Aretede. ${ }^{11}$ El objetivo fundacional de ese colectivo tenía como eje el efectivo ejercicio de los derechos indígenas y el rescate de la memoria de la resistencia de las poblaciones aborígenes de la zona. Las primeras actividades que impulsó estuvieron dedicadas a otorgar trascendencia pública a las demandas en relación con el derecho a la tierra.

Otro de los puntos por destacar en la memoria de la fM Comunitaria La Voz Indígena es el rol que cumplió la sede regional Tartagal-Universidad Nacional de Salta (SRT-UNSa), pues desde las cátedras de la carrera de Comunicación Social se iniciaron los talleres de capacitación como parte de las tareas de extensión que culminaron con la puesta al aire de la radio.

El grupo fundador de la Aretede fue el que asistió al primer taller de radio organizado en la sede regional Tartagal de la Universidad Nacional de Salta. A partir de 2003, la capacitación se comenzó a realizar en las comunidades vecinas a la ciudad, posibilitando la incorporación de comunicadores jóvenes, que hasta ese momento no habían podido llegar a la universidad. La voz de una de las protagonistas del proyecto da cuenta del valor que les asignaron a la capacitación y a la radio:

Hemos ido a capacitarnos en la universidad. Somos las primeras, fuimos 20 personas que íbamos a la capacitación allá en la universidad, y de esa manera se consiguió lo que es hoy tener una radio indígena que era tan necesaria en la zona. Yo siempre decía que el espacio para las comunidades indígenas era limitado en Tartagal, porque todas las radios tienen su dueño, son privadas y era muy difícil que nos den un espacio para que las comunidades puedan contar sus vivencias, las necesidades que tienen. Hoy contamos con eso, la importancia de haber ido a capacitarnos en la universidad y ver, el sacrificio de ir, y un día tener la oportunidad de ganar un premio presidencial y de esa manera se empezó con la radio.

Es muy valorable lo que tenemos. Yo siempre digo que es una cosa grandísima por la forma en que

la hemos conseguido, dejando nuestras casas, nuestras familias (Cristina, comunicadora indígena de la comunidad 9 de Julio de Tartagal).

En el año 2002, al terminar el primer taller de capacitación de la universidad, se puso al aire el programa $L a$ Voz del Pueblo Indígena en LRA 25 Radio Nacional Tartagal, que fue el puntapié inicial de una forma diferente de mediatizar la problemática indígena en el departamento General San Martín.

Hasta ese momento, la realidad era interpretada y hecha pública por los comunicadores de las radios locales, ninguno de ellos aborigen. A partir de la primera transmisión del programa, los temas eran pensados y expresados por los mismos miembros de los pueblos originarios, impugnando con ello la lógica predominante en los medios locales. Con este desplazamiento se logró poner en la agenda las temáticas que no se abordaban desde los otros medios; visibilizar los problemas que trae aparejada la siembra de la soja; los obstáculos al acceso a la salud, debido a la falta de personal bilingüe en el hospital local. Exponer las situaciones antes mencionadas en lengua propia y ante una audiencia

10 El departamento General San Martín se encuentra al norte de Salta y se constituye en uno de los espacios más ricos en diversidad cultural de Argentina. Conviven pueblos indígenas como el wichí, guaraní, tapiete, chulupi, toba, chane o chorote, junto con los criollos e inmigrantes que llegaron a la zona. El departamento limita con el Estado Plurinacional de Bolivia y la República de Paraguay.

11 Asociación sin fines de lucro que gestiona, desde los aspectos administrativos, el colectivo de la radio. 


\section{DISERTACIONES}

ESTUDIOS

Comunicación indigena en América Latina

ISSN: $1856-9536$

Doi: http://dx.doi.org/10.12804/revistas.urosario.edu.co/disertaciones/a.5745

Volumen 11, Número 2 / Julio-diciembre 2018

Versión PDF para imprimir desde

http://revistas.urosario.edu.co/index.php/disertaciones

que no está integrada solo por pueblos originarios constituye una muestra de la necesidad de conservar la lengua a pesar de las fuertes muestras de racismo que atraviesan a una sociedad como la tartagalense.

Asumir el desafío de expresarse en lengua indígena en una radio del Estado conllevaba los riesgos propios de una interpelación a las formas en que se concebía el derecho a la comunicación, que no se limitaba solo a los escuchas de la radio, sino que ponía en tensión las formas jurídico-políticas a partir de las cuales el Estado procuraba reconocer ese derecho. Retomando las palabras de Grimson, era posible palpar que "si en un contexto específico dos lenguas que conviven nunca tienen valores sociales idénticos, incluso aunque ambas sean oficiales, esto plantea un conflicto que podrá derivar en diferentes situaciones" (2001, p. 68).

La presencia de esas voces tenía la forma de un acontecimiento político comunicacional sin precedentes. La palabra socialmente estigmatizada - que circulaba de forma soterrada en las calles de la ciudad, la polifonía maldita que deambulaba en las recorridas de la mendicidad urbana - era escuchada con fidelidad radiofónica. La radiofonía operaba como un espacio de legitimación simbólica de la palabra indígena y con ello reeditaba en una nueva clave toda una serie de interrogantes frecuentes sobre el modo en que se articulaban los dispositivos tecnológicos con la palabra.

Para que esa voz no fuese atrapada por los formatos radiofónicos ya instituidos, para que no se produjese una captura del componente crítico de esta irrupción, había que sortear el obstáculo no solo de la proscripción social, sino también del aislamiento geográfico. Fue preciso respaldar el proceso en una fuerte apuesta por el fortalecimiento de la participación de las comunidades indígenas. En ese rumbo, en ocasiones se facilitaba el acceso a la comunicación a través de llamadas telefónicas, como una forma de superar la falta de recursos para trasladarse hasta parajes vecinos o por el simple hecho de que el estado de las rutas - como consecuencia del clima-volvía dichos lugares inaccesibles.

La diversidad es un rasgo propio de la vida humana. Reconocerla como tal es una tarea que exige agudizar las formas de percepción y un profundo ejercicio de descentramiento de nuestras perspectivas sociales, políticas y culturales. Pero esos reconocimientos no se llevan a cabo en espacios neutralizados de relaciones de poder, ni desprovistos de los sentidos que producen los discursos. En ese orden de ideas, una de las principales características de la radio consiste en reflejar y dar desde la diversidad cultural y étnica del colectivo que la constituye.

Las heterogeneidades del territorio son audibles en su discurso radiofónico. Se escuchan programas conducidos por comunicadores guaraníes, wichís, tapietes, chanes, tobas, chorotes o chulupies. Esto genera una trama compleja de formas del decir, del actuar y del sentir difíciles de abordar desde una perspectiva analítica. Sin embargo, a pesar de las diferencias, la identidad indígena del medio se manifiesta como resultado de un proceso muy dinámico de conjugación de las diferencias. El carácter único, en el sentido de singularidad del medio, no hace homogénea la diversidad bajo un discurso monológico, ni oculta el hecho de que cada palabra que emite la radio pone de manifiesto la pertenencia a alguno de los distintos pueblos indígenas.

Una segunda característica es la transversalidad que tiene la demanda de derechos en toda la programación. En las doce horas diarias de programación podemos escuchar spots y programas que informan sobre el derecho a la tierra, a la identidad, a la diversidad sexual, a la educación bilingüe, a la comunicación con identidad, a la no violencia contra las mujeres indígenas, a la no discriminación o al cuidado del medio ambiente. En los últimos años se incorporó la demanda de que Argentina se convierta en un Estado plurinacional. Pero esto también puede ser reconocido en la variedad de sus formatos radiofónicos, que van desde el spot hasta los radioteatros. 


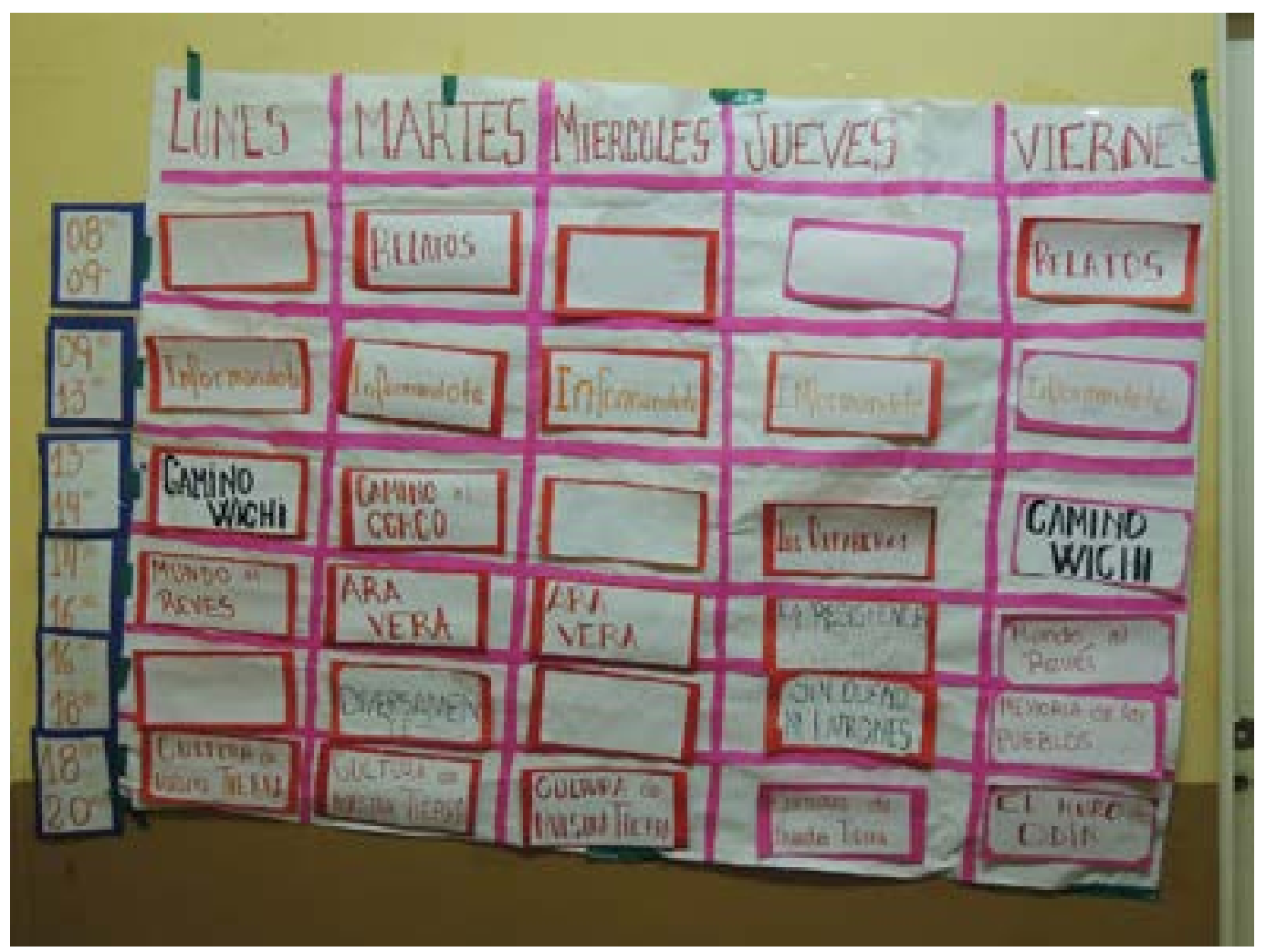

Figura 1. Programación de radio

Fuente: fotografía de la autora.

Una tercera característica que atraviesa al medio, en todas sus dimensiones, es la búsqueda constante por rememorar la resistencia indígena local a la colonización del territorio. La historia oficial de la provincia de Salta no incorporó lo que sucedió entre las márgenes de los ríos Bermejo y Pilcomayo, y esa falta se advierte en todos los pueblos, siendo más aguda entre wichís y tobas.

La radio generó piezas radiofónicas con contenidos referidos a la historia indígena local: "Calendario indígena" y en radioteatro "Las voces del destierro". El primero marca mes a mes las fechas de la resistencia indígena comprendida entre el sur del Estado plurinacional de Bolivia y el norte de Argentina. En tanto, el radioteatro relata la resistencia de Camba, cacique de la resistencia toba del Bermejo, que se enfrentó a los ejércitos de Romero Victorica en 1884, durante la presidencia del general Roca. Otra de las producciones es la historia de la comunidad wichí en el departamento.

Este texto se planteó como objetivo dilucidar las implicancias de la noción de identidad en directa relación con la comunicación, intentando trasvasar los límites que por mucho tiempo impuso al término la antropología social. Para dar cuenta del objetivo político que pone en juego esta radio, es necesario hacer mención a una cuestión central de la problemática indígena regional, como lo es la ocupación de la tierra en el departamento General San Martín. 


\section{DISERTACIONES}

ESTUDIOS

Comunicación indigena en América Latina

ISSN: 1856-9536

Doi: http://dx.doi.org/10.12804/revistas.urosario.edu.co/disertaciones/a.5745

Volumen 11, Número 2 / Julio-diciembre 2018

Versión PDF para imprimir desde

http://revistas.urosario.edu.co/index.php/disertaciones

En términos generales puede sostenerse que, como en el resto de América Latina, el problema se origina luego de la colonización del continente, pero en la zona norte de Argentina, la apropiación de las tierras sobrevino con el proceso de formación del Estado nacional, lo que convirtió a los pueblos originarios en usurpadores de las tierras en la que siempre estuvieron asentados. Con el avance de la frontera agropecuaria, esta situación se agudizó debido a los constantes desalojos a los que son sometidos.

Si bien la Ley Nacional $26160^{12}$ otorgó visibilidad a los reclamos territoriales, en esta zona todavía no ha brindado soluciones de ningún tipo. Para graficar el panorama resulta pertinente recurrir a un estudio realizado por la unsa y el Ministerio de Justicia, cuyos resultados se publicaron en el texto de Buliubasich y González (2009) Los pueblos indígenas de la provincia de Salta: la posesión y el dominio de sus tierras. Las autoras sostienen que la situación de las comunidades indígenas es muy comprometida, pues se pone de manifiesto que, fundamentalmente, las tierras que habitan están destinadas a atender las necesidades habitacionales $\mathrm{y}$, en un porcentaje bastante menor, permiten actividades vinculadas con la caza, la recolección o el cultivo.

La programación de una radio comunitaria expresa el objetivo político que la define. En la FM Comunitaria La Voz Indígena, la construcción comunitaria se configuró a través de una serie de reuniones y asambleas. Desde la puesta al aire hasta hoy, la programación se modificó una vez al año, sin que ese cambio implique dejar de dar cuenta de la relación del discurso que emite y la cotidianeidad de las comunidades. En este sentido, la radio mantiene como ejes principales los temas referidos a la resistencia indígena, la tenencia de la tierra y la reivindicación de derechos.

\section{A modo de conclusión}

La programación de una radio brinda una herramienta a través de la cual el territorio es el espacio de reproducción de la sociedad y de la cultura de los pueblos originarios y, en ese sentido, es el principal soporte de la identidad. La pérdida paulatina y constante de los territorios y recursos naturales produce, desde hace muchos años, una importante desestructuración social que tiene como consecuencia la pérdida de cultura y el debilitamiento de la identidad.

En este contexto social, se producen las luchas por el sentido que pugnan por expresarse y reivindican el derecho más básico, así como el más trascendente para los pueblos originarios: el territorio. Este reclamo es también un grito de cultura y un llamado desde la identidad, que en momentos de crisis emergen desde lo profundo de sus pueblos.

La relación entre estos aspectos es indisociable y su abordaje permitió evaluar, en este texto, los elementos de programación vinculados con esta temática, transitando al terreno de la identidad, a evaluar sus manifestaciones, a entender su contexto y a analizar su proceso en el interior de la radio.

12 La ley, y su posterior prórroga, declara la emergencia en materia de posición y propiedad de la tierra para los pueblos indígenas de Argentina, se firmó en 2006. El artículo $2^{\circ}$ expresa: "Suspéndase por el plazo de la emergencia declarada, la ejecución de sentencias, actos procesales o administrativos, cuyo objeto sea el desalojo o desocupación de las tierras contempladas en el artículo $1^{\circ}$. La posesión debe ser actual, tradicional, pública y encontrarse fehacientemente acreditada". La misma ley establece la realización de un relevamiento que dé cuenta de la situación dominal de las tierras, proceso que aún no terminó y está avanzado en un $49 \%$. 


\section{DISERTACIONES}

ESTUDIOS

Comunicación indigena en América Latina

ISSN: $1856-9536$

Doi: http://dx.doi.org/10.12804/revistas.urosario.edu.co/disertaciones/a.5745

Volumen 11, Número 2/ Julio-diciembre 2018

Versión PDF para imprimir desde

http://revistas.urosario.edu.co/index.php/disertaciones

A las condiciones materiales que generaron la pérdida acelerada del territorio, se interponen los períodos de lucha por la tierra, que son coyunturas en las cuales emergen y se conjugan diversos elementos de resistencia que las comunidades ponen en juego, anclados en aspectos socioculturales de los pueblos.

El devenir de los procesos está determinado por la fuerza represiva del Estado y el desgaste de la resistencia de las comunidades. Ahora bien, estos son momentos clave en la emergencia y el fortalecimiento de la identidad de los pueblos originarios, que alzan su voz en la lucha por los territorios. La disputa por el sentido y la necesidad estratégica de hacerse escuchar son detonantes en todos los casos de los movimientos de resistencia. Las situaciones en las que estas luchas surgieron, posteriormente a la puesta en el aire de La Voz Indígena, han tenido una inmediata manifestación en la radio, impactando tanto en la organización y la rutina del colectivo de La Voz Indígena, como también en las comunidades involucradas.

Las luchas por la resistencia producen, entre otras cosas, un desborde de elementos que se sobrevienen casi sin tener contención. Las reflexiones sobre las pérdidas, la aculturación o la discriminación necesitan canalizarse y tener interlocutores para sumar a la lucha. En esta situación, La Voz Indígena se constituye en el medio propicio para expresar este desborde de reclamos al Estado, para manifestar sus verdades a la población de Tartagal, pero también para interpelar a sus pueblos, incitándolos a la lucha y a llevar a sus comunidades las voces de los antiguos que gritan desde el pasado su derecho a la tierra, proclamando su identidad originaria.

Al momento de finalizar la exposición de esta investigación, es preciso retomar la cuestión central a partir de la cual realizamos el recorrido, es decir, regresar al planteamiento del problema para intentar dilucidar si la comunicación con identidad se configura como una alternativa ante la comunicación comunitaria en el caso de la radio La Voz Indígena. En relación con ello, es preciso remarcar que no se trata de agotar el análisis de la comunicación con identidad, particularmente si se tiene presente que las categorías, a partir de las cuales se produce la adjetivación de la comunicación emancipadora, cobran sentido en el marco de las experiencias que posibilitan y de las luchas que sostienen.

Menos aún pretendemos ocultar las dificultades propias de todo intento por establecer delimitaciones definitivas entre las formas de encarnar la comunicación social, poniendo el énfasis en el interés emancipatorio. La evaluación crítica del alcance de lo popular, lo alternativo y lo comunitario forma parte de un debate abierto y fructífero de gran actualidad.

Es posible sostener que el impacto de la Ley de Servicios de Comunicación Audiovisual ha representado una conquista de enormes dimensiones para todo el ámbito de la comunicación comunitaria, alternativa o popular. En el caso de la comunicación indígena, ha instalado una categoría fundamental para pensar la relación entre el reconocimiento de las identidades de los pueblos originarios de nuestro país y su derecho a la palabra.

Al fijar los objetivos que guiaron este texto, la propuesta fue investigar el caso de La Voz Indígena como un medio que se reconoce como comunitario, y saber si comparte características con la comunicación con identidad. Nos centramos en las particularidades de esta última en el modo de vincularse con la tierra, con el medio ambiente, con la pluralidad cultural y lingüística, y con el modo de organización social. Esta perspectiva la diferencia de las otras formas de comunicación política emancipadora por varios aspectos que se hacen necesarios retomar.

En conclusión, esta radio genera formas particulares de vincularse con las comunidades indígenas del departamento General San Martín. Cuando decimos particulares nos referimos, por ejemplo, al modo de conformar la 


\section{DISERTACIONES}

ESTUDIOS

Comunicación indigena en América Latina

ISSN: 1856-9536

Doi: http://dx.doi.org/10.12804/revistas.urosario.edu.co/disertaciones/a.5745

Volumen 11, Número 2 / Julio-diciembre 2018

Versión PDF para imprimir desde

http://revistas.urosario.edu.co/index.php/disertaciones

agenda periodística, pues instala como tema permanente el derecho al territorio o la memoria étnica. Esta decisión no es azarosa, sino fruto de la cotidianeidad que solo puede ser noticia en ese medio.

Las radios comunitarias trabajan temáticas parecidas a los medios comerciales, pero desde una perspectiva política que involucra a la comunidad y no a los intereses del mercado o los poderes hegemónicos. La Voz Indígena no siempre incluye en su agenda las noticias que para el resto de los medios son tales, lo que, en términos de Gomis (1991), podríamos denominar "las más noticias"; este medio prioriza el análisis y publicación de la problemática indígena, centralizada en la tierra y en muchos casos emitida en las lenguas propias. El presente de la radio es en el presente de lo que sucede en las comunidades.

Las transformaciones que de ello se derivan pueden reconocerse en el ámbito de la programación del medio radial y en el modo mismo de su gestión. Pero así como no existen liberaciones definitivas ni opresiones infinitas, lo que aparece con la ampliación de los derechos es un nuevo campo de problematización de las prácticas y los discursos a partir de las cuales nos constituimos como sujetos y como colectivos.

En este nuevo espacio emerge la necesidad de repensar la relación entre las comunidades indígenas y la comunidad académica interesada en alentar la lucha contra las discriminaciones y las injusticias que vienen sufriendo los pueblos originarios. Volver a pensar las relaciones entre saberes y prácticas es la vía que nos conduce al compromiso con la profundización de los análisis en futuras investigaciones, con la ampliación del conjunto de los casos en que se hace presente la tensión entre la comunicación con identidad y la comunicación comunitaria, pero sobre todo con la tarea de brindar herramientas teóricas para que la conquista de derechos no obture el devenir crítico de las minorías. Es por eso que reconocer la adscripción de la radio La Voz Indígena al campo de la comunicación comunitaria, al modo en que aún la entendemos, forma parte precisamente del reconocimiento de las formas en que se conjuga en ese medio de comunicación singular la apuesta por la conquista de las libertades que todavía nos resultan necesarias.

La afirmación de un conjunto de identidades (en este caso de las comunidades aborígenes que habitan en el departamento General San Martín) desde sus singularidades constituye, en definitiva, un camino para el afianzamiento y la conquista de ciertos derechos ciudadanos.

\section{Referencias}

1. Beltrán, L., Herrera, K., Pinto, E., \& Torrico, E. (2008). La comunicación antes de Colón, tipos y formas en Mesoamérica y los Andes. La Paz: Centro Interdisciplinario Boliviano de Estudios de la Comunicación.

2. Buliubasich, C., \& González, A. (2009). Los pueblos indígenas de la provincia de Salta: la posesión y el dominio de sus tierras. Salta: Cartoon S. A.

3. Deleuze, G. (1996). Conversaciones. Valencia: Pretexto.

4. Doyle, M. (2012). Los medios masivos de comunicación en las luchas de los pueblos indígenas. Abordajes desde los estudios sobre comunicación en América Latina (Tesis de maestría no publicada, Centro de Estudios Avanzados, Universidad Nacional de Córdoba, Córdoba, Argentina).

5. Foucault, M. (1985). Poderes y estrategia. En Un diálogo sobre el poder y otras conversaciones. Madrid: Alianza Editorial.

6. Grimson, A. (2001). Interculturalidad y comunicación. Colombia: Norma. 
7. Huergo, J., Morawicki, K., \& Ferreyra, L. (2006). Una experiencia de radio comunitaria con aborígenes wichí. Comunicar, Revista Científica Iberoamericana de Comunicación y Educación, (26), 103-110.

8. Lizondo, L., \& Ortega, M. (2013). Comunicación con identidad, entre la Ley de Servicios de Comunicación Audiovisual y la comunicación popular. En L. Valdés \& S. Morales (Comps.), Industrias culturales, medios y públicos: de la recepción a la apropiación ( $1^{\mathrm{a}}$ ed.). Córdoba: Universidad Nacional de Córdoba.

9. Marques de Melo, J. (1998). Teorías de la comunicación. Paradigmas latinoamericanos.

10. Rodríguez, C., \& El'Gazi, J. (2007). La poética de la radio indígena en Colombia. Ya no es posible el silencio. Colombia.

11. Zambrano, C. (2006). Ejes políticos de la diversidad cultural. Bogotá: Siglo del Hombre Editores-Universidad Nacional de Colombia.

\section{Consultas de documentos}

1. Argentina, Cámara de Diputados de la Nación, sesiones ordinarias 2009. Proyecto de Ley de Servicios de Comunicación Audiovisual, audiencias públicas. Comisiones de Comunicaciones e Informática, de Presupuesto y Hacienda y de Libertad de Expresión. Apartado I. Reproducción textual de los documentos presentados.

2. Argentina, Constitución Nacional. Recuperado de http://www.senado.gov.ar/bundles/senadoparlamentario/pdf/institucional/constitucion_nacional_argentina.pdf

3. onu. Declaración de las Naciones Unidas. Recuperado de http://www.unicef.org/argentina/spanish/derechos_indigenas.pdf 